\title{
Tool with a thin film stress sensor for measuring the stress on the rake face in orthogonal cutting
}

\author{
Toshiyuki OBIKAWA*, Kenji YAGI** and Mamoru HAYASHI*** \\ *Tokyo Denki University \\ 5 Senju Asahi-cho, Adachi-ku, Tokyo 120-8551, Japan \\ E-mail: obikawa@mail.dendai.ac.jp \\ **Research and Innovation Center, Mitsubishi Heavy Industries Ltd. \\ 5-717-1 Fukahori-machi, Nagasaki 851-0392, Japan \\ ***Resonic Japan Ltd. \\ 1-7-6 Oogami, Ayase-city, Kanagawa 252-1104, Japan
}

Received: 27 August 2020; Revised: 12 November 2020; Accepted: 2 February 2021

\begin{abstract}
The evaluation of stress and temperature on the tool faces during machining is very important for understanding the fundamental mechanisms of cutting processes, developing cutting tools, optimizing cutting conditions. Although cutting temperature has been often measured using the tool-chip thermocouple method, a two-color pyrometer, thermography, etc., measurement of stress on the tool face has been hardly reported. For this reason, a cutting tool with a thin film stress sensor in a layer structure of coating on the rake face was developed for orthogonal cutting. The film sensor was made of manganin, a copper-manganese-nickel alloy having piezoresistive effect. The manganin was coated on the rake face of polished tool insert of silicon nitride by magnetron sputtering in a specific pattern having a line 30 micrometer wide and 0.2 micrometer thick along the cutting edge. Then, the rake face was further coated with silicon nitride for protecting the thin stress sensor. After the calibration of the sensor, the tool was applied to orthogonal cutting experiment, in which MC Nylon ${ }^{\circledR}$ and polyvinyl chloride were machined at a very low cutting speed. For four levels of uncut chip thickness from 0.05 to $0.20 \mathrm{~mm}$ the stress was measured for MC Nylon. A trapezoidal distribution of normal stress, which had been reported for soft materials by photoelasticity method, was also obtained from the measured stresses in this study.
\end{abstract}

Keywords : Thin film stress sensor, Cutting tool, Manganin with piezoresistive effect, Orthogonal cutting, Stress change with cutting time

\section{Introduction}

Stress acting on the cutting tool face has a great influence on the tool wear, cutting temperature, machining accuracy, etc. It also significantly affects the mechanics of machining and the optimization of cutting conditions. Thus, stress distribution on the rake face in orthogonal cutting have been measured using several pairs of split tools with different split positions from the cutting edge (Kato et al., 1972; Usui et al., 1978; Obikawa et al., 1997) and photoelasticity method (Usui and Takeyama, 1960; Chandrasekaran and Kapoor, 1965; Bagchi and Wright, 1987). However, the measurement of the stresses using these methods was very difficult and time consuming. Probably, stress measurement on the tool face by these methods has not been reported in 21 st century according to our literature survey. In contrast, cutting forces that can be easily measured with a tool dynamometer is used as mechanical information for evaluating cutting and tool conditions such as chatter vibration, tool wear, and tool breakage. The signal processing of cutting forces and the application of an artificial neural network could help more reliable tool condition monitoring (Obikawa and Shinozuka, 2004). However, it is indispensable to know the stress on the tool surface for the design and development of high performance tools with advanced coating materials. Finite element analysis is often used to predict stresses on the tool face as well as chip formation and cutting temperature for machining various materials under different cutting conditions (Obikawa and Usui, 1996; Ohbuchi and Obikawa, 2003). The analysis results requires the verification based on the 
measured values, but only cutting forces measured for specific conditions are usually used for the verification. Therefore, the establishment of a new method for measuring the stress on the tool face would contribute to further development of machining science and technology.

Recently, thin film microsensors, which can measure the mechanical and thermal conditions of specific local positions, have been applied to tribological condition monitoring. With regard to thin film sensors for cutting tools, there are some researches on the development of tools with built-in thin film thermocouple sensors in the coating layer structures, which were applied for turning aluminum alloy (Basti et al., 2006) and carbon steel (Shinozuka et al., 2008). However, there is no precedent for the measurement of the stress on the tool rake face with a thin film sensor, although the contact pressure and load were measured using a thin film stress sensor of material with a piezoresistive effect and a small strain sensitivity or gauge factor. Mihara et al. (2010) applied thin film sensors of manganin (Cu-Mn-Ni alloy), which were fabricated on the contact area of one of pair of rollers, for the measurement of the contact pressure between the two rollers. Biehl et al. (2006) used thin film sensors of amorphous diamond-like carbon (DLC) for fabricating a radial bearing ring with DLC force sensor structures and monitoring the change in tribological environment. The purpose of this study is to develop a tool with a thin film stress sensor of manganin in a layer structure of coating and to measure the normal stress on the tool rake face during orthogonal cutting.

\section{Experimental methods}

\subsection{Fabrication of a tool with a thin film stress sensor}

A ceramic tool insert of silicon nitride with a shape of SNMN120408TN was used as the tool matrix for this study. Although an alumina insert had been used as the tool matrix for a tool with thin film thermocouple sensors of nickel and nichrome (Basti et al., 2006; Shinozuka et al., 2008), it was changed for a silicon nitride insert because the oxidation of manganin by the diffusion of oxygen from $\mathrm{Al}_{2} \mathrm{O}_{3}$ insert at high temperature during coating processes may cause the degradation of the piezoresistive effect. The manganin used had a composition of $87.4 \%$ copper, $9.6 \%$ manganese, and $3 \%$ nickel. Its piezoresistive effect has a smaller sensitivity to temperature than a typical manganin of $86 \%$ copper, $12 \%$ manganese, and $2 \%$ nickel.

Figure 1 schematically shows the fabrication process of a tool with a thin film stress sensor on the rake face. After the tool rake face of the insert was polished to the surface roughness value less than $0.01 \mu \mathrm{m} \mathrm{Ra,} 0.2 \mu \mathrm{m}$ thick $\mathrm{Si}_{3} \mathrm{~N}_{4}$ was coated on the tool face using high-frequency magnetron sputtering to reduce the area of countless pores on the polished tool face, which were inevitable for a sintered ceramics. Then, $0.2 \mu \mathrm{m}$ thick manganin was further coated on the tool face by magnetron sputtering.
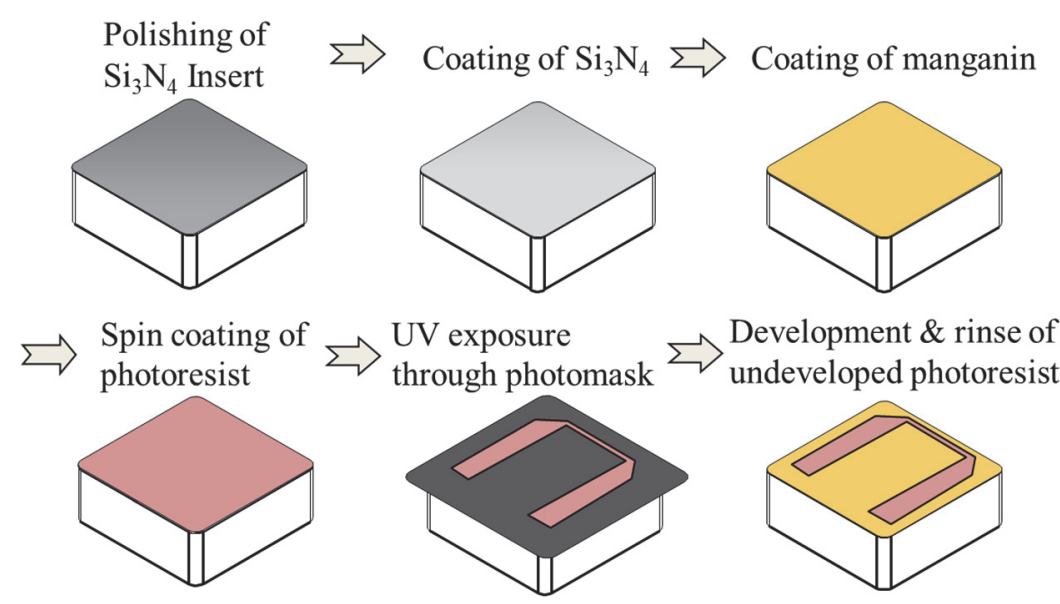

$\Rightarrow \begin{aligned} & \text { Etching of manganin \& } \\ & \text { removal of photoresist }\end{aligned} \Rightarrow$ Protective coating of $\mathrm{Si}_{3} \mathrm{~N}_{4}$

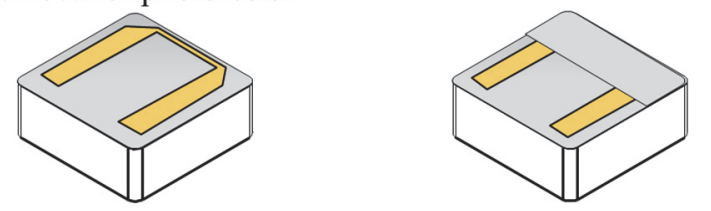

Fig. 1 Schematic diagram of fabrication process of a tool with a thin film stress sensor. 
The sensor circuit of manganin was patterned by the wet etching of the thin manganin film using photolithography. Figure 2 shows its pattern for orthogonal cutting used in this study. The sensing part of manganin, $3.0 \mathrm{~mm}$ long, $30 \mu \mathrm{m}$ wide, and $0.2 \mu \mathrm{m}$ thick, was parallel to and $0.20 \mathrm{~mm}$ away from the cutting edge. Its both sides were connected to lead parts, which are very wide to reduce their electric resistances. A square frame surrounding the pattern of sensor circuit, which had an insert shape with four round corners, was used for positioning of the mask placed on an insert.

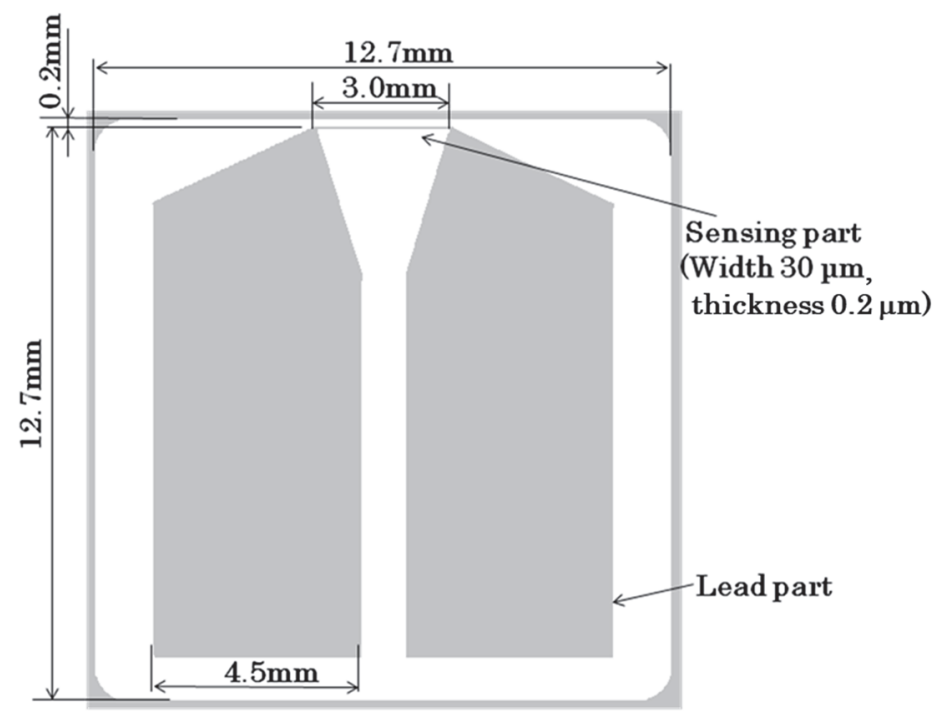

Fig. 2 Sensor circuit pattern of manganin.

Finally, $1.0 \mu \mathrm{m}$ thick $\mathrm{Si}_{3} \mathrm{~N}_{4}$ was coated on the tool face to protect the upper part of the sensor pattern as shown in Fig. 1 (see also Fig. 6 below). During the coating processes the substrate temperature was set at $450{ }^{\circ} \mathrm{C}$ for the first layer of $\mathrm{Si}_{3} \mathrm{~N}_{4}$ and the manganin, whilst it was $200{ }^{\circ} \mathrm{C}$ for the protective layer of $\mathrm{Si}_{3} \mathrm{~N}_{4}$. This is because the piezoresistive effect of manganin disappeared and the electric resistance of manganin itself decreased dramatically after the protective coating of $\mathrm{Si}_{3} \mathrm{~N}_{4}$ when the substrate temperature was $450{ }^{\circ} \mathrm{C}$. For this reason, the substrate temperature was decreased to the lowest temperature for making $\mathrm{Si}_{3} \mathrm{~N}_{4}$ film on the tool face with quality enough for machining, but naturally the coating rate had to be reduced.

The small change in the electric resistance of the sensing part of manganin due to the pressure or normal stress acting on the part was measured using a Wheatstone bridge circuit schematically shown in Fig. 3. The terminals of the bridge circuit and the lead parts of the sensor on the tool face were connected mechanically using a clamping jig. The calibration of the thin film sensor was conducted in a pressure vessel using an electrically insulating fluid called Fluorinert ${ }^{\circledR}$ as the pressure medium. Figure 4 shows the pressure vessel under the calibration of manganin piezoresistivity and a schematic diagram of the calibration system. The change in the output voltage of the bridge circuit with pressure was recorded for an applied input voltage of $2 \mathrm{~V}$ when the sensor circuit was pressurized up to $180 \mathrm{MPa}$ and decompressed down to the atmospheric pressure in steps of $20 \mathrm{MPa}$ with a holding time of $1 \mathrm{~min}$ at each holding pressure.

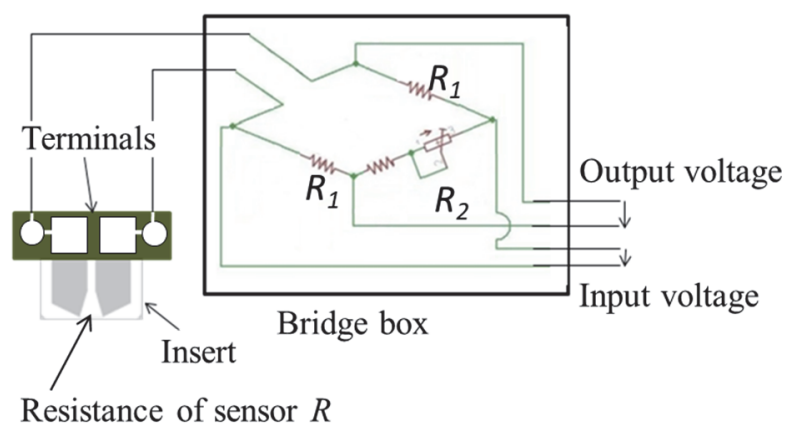

Fig. 3 Bridge circuit for measuring the normal stress on the rake face. 

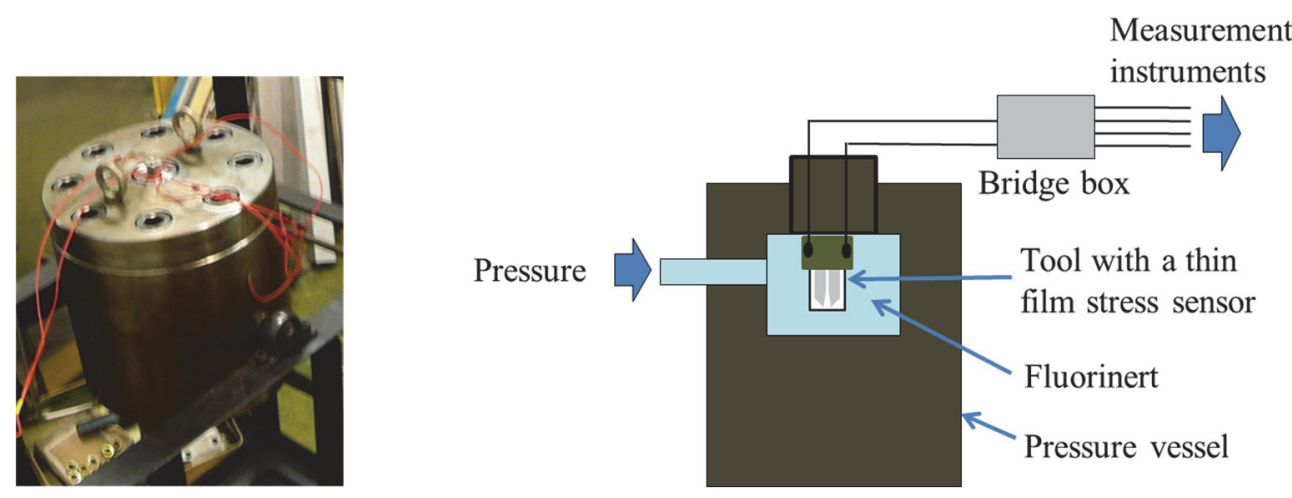

Fig. 4 Pressure vessel used for the calibration of manganin piezoresistivity and its schematic diagram.

\subsection{Cutting experiments}

Orthogonal cutting experiments schematically shown in Fig. 5 were conducted using a developed tool under dry conditions on a desktop type of milling machine tool, which had been used for, for example, micromilling using a micro ball end mill with a textured rake face (Obikawa and Kani, 2012), and its spindle was removed for this study. Work materials to be cut were $\mathrm{MC}$ Nylon ${ }^{\circledR}$ and polyvinyl chloride, which have quite different properties each other. A small plate of a workpiece was fixed to a work holder on a piezoelectric cutting dynamometer. Mild cutting conditions were selected because the coating of $\mathrm{Si}_{3} \mathrm{~N}_{4}$ on the rake face was very thin and the sensing part of manganin might reduce the adhesive strength of coating: cutting speed $6.0 \mathrm{~mm} / \mathrm{min}$, width of cut $2.0 \mathrm{~mm}$, uncut chip thickness $0.05,0.10,0.15$, and $0.20 \mathrm{~mm}$, cutting length $8.0 \mathrm{~mm}$, rake angle $-5^{\circ}$, and relief angle $5^{\circ}$. The output of stress sensor and cutting and thrust forces were recorded during cutting.

Marking ink was painted on the rake face of the tool before each cutting experiment for determining the tool-chip contact length. It was wiped away by a chip produced during cutting. Hence, the tool-chip contact length was determined with a digital microscope by measuring the mean width of wiped area of marking ink from the cutting edge along the chip flow direction.

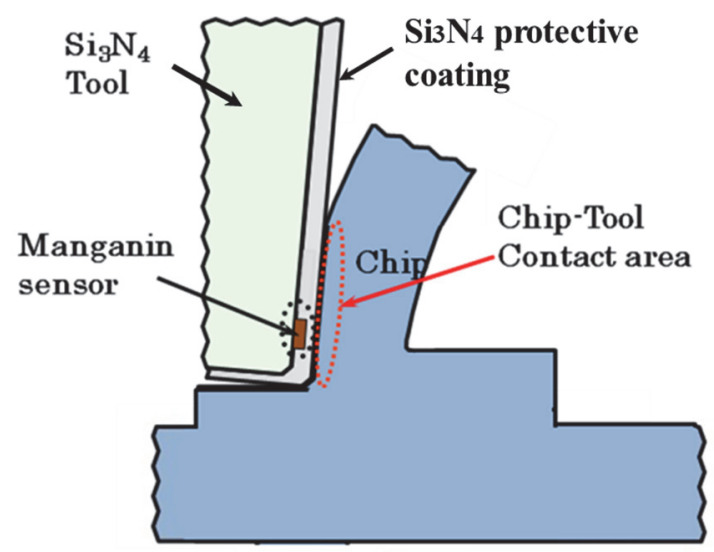

Fig. 5 Schematic diagram of orthogonal cutting using a tool with a thin film stress sensor.

\section{Results and discussion}

Figure 6 shows the fabricated tool with a thin film stress sensor and the magnified view of the connection portion between the sensing and lead parts. The sensing part was made without defect, while a lead part was not perfectly etched to a designed shape probably because the coating of materials were conducted at a rather low substrate temperature. The upper half part of the rake face was coated with a protective layer of $\mathrm{Si}_{3} \mathrm{~N}_{4}$. This very thin $\mathrm{Si}_{3} \mathrm{~N}_{4}$ layer was transparent, and thus, the coating of manganin can be seen through the $\mathrm{Si}_{3} \mathrm{~N}_{4}$ layer. This tool was clamped on a tool holder for orthogonal cutting as shown in Fig. 7. A board with two terminals for connecting the sensor circuit of manganin and 
bridge box as schematically shown in Fig.3 was pressed by a clamping pin to the tool rake face so that the two terminals had mechanical contact with two lead parts of the sensor.

Figure 8 shows the relationship between the output of the stress sensor and applied pressure, which was obtained through the calibration in a pressure vessel. A linear equation written in Fig. 8 for the relationship was obtained by the least square method with a good coefficient of determination $\mathrm{R}^{2}$ of 0.98845 .

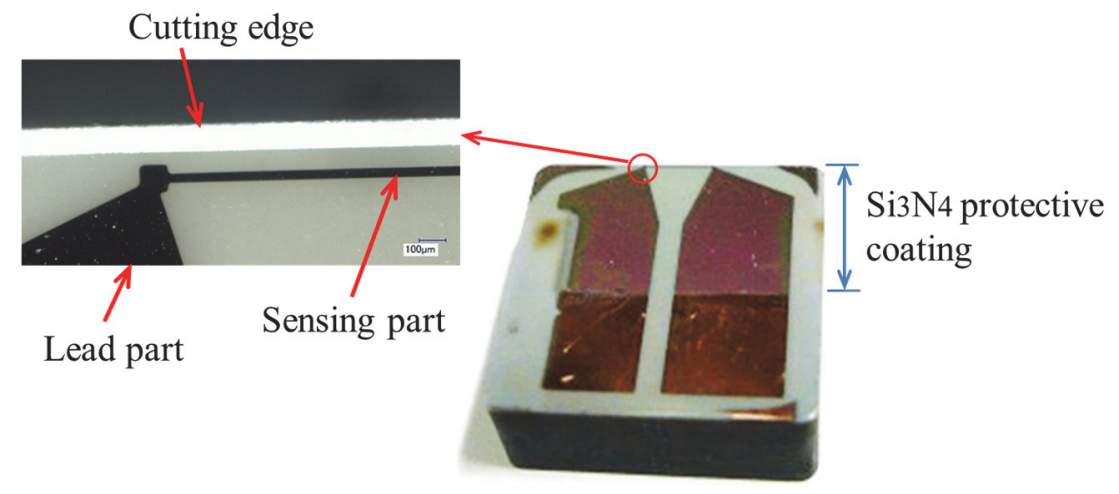

Fig. 6 Fabricated tool with a thin film stress sensor and magnified view of connecting portion of sensing and lead parts.

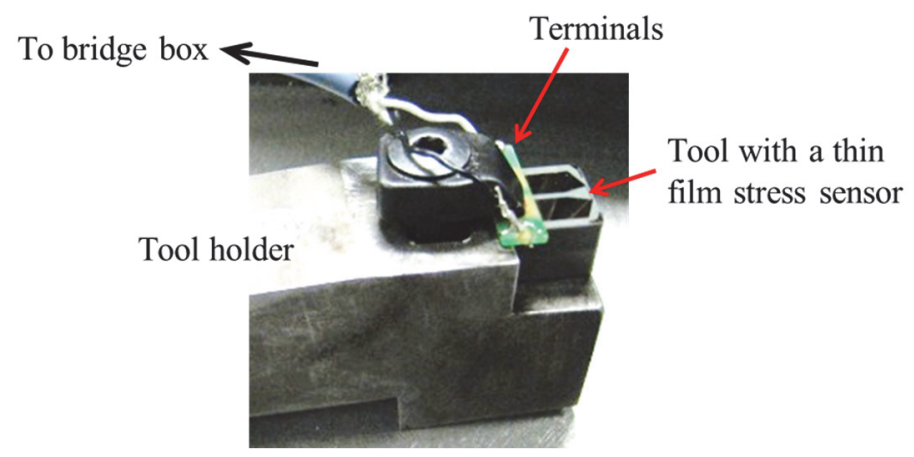

Fig. 7 Tool with a thin film stress sensor clamped on a tool holder.

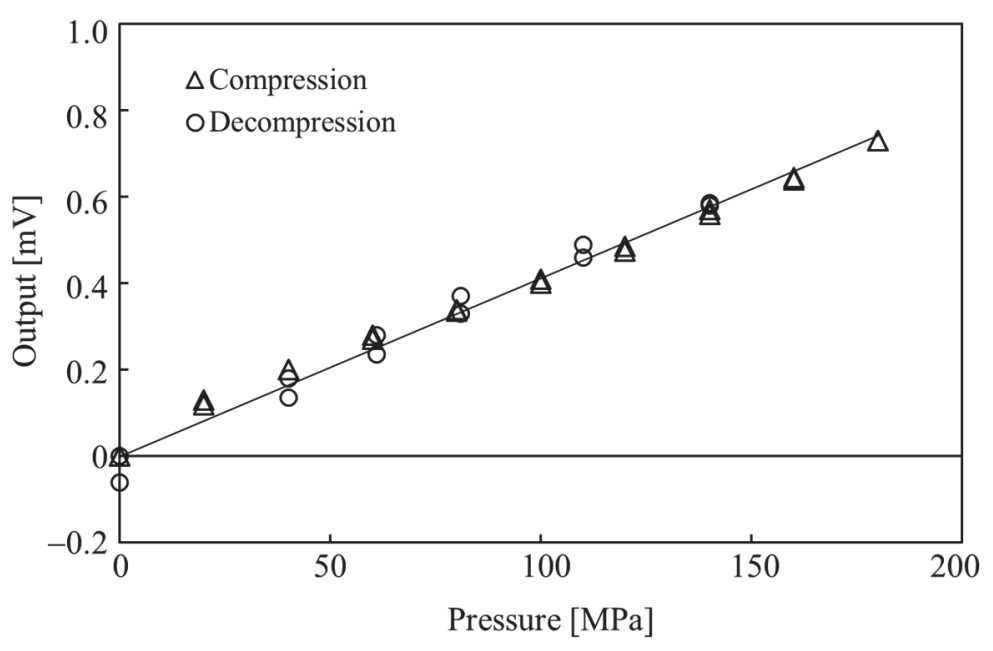

Fig. 8 Relationship between the output of stress sensor and pressure.

Figures 9 and 10 show the changes in cutting and thrust forces for the orthogonal cutting of MC Nylon at an uncut chip thickness of $0.20 \mathrm{~mm}$ and the changes in the normal stress calculated from the sensor outputs for four different uncut chip thicknesses, respectively. The cutting forces increased rapidly at the beginning of cutting and then increased gradually until they tended to be saturated after a short distance of cutting. In contrast, the normal stress at an uncut chip 
thickness of $0.20 \mathrm{~mm}$ seemed to be almost constant over the cutting time except a single strong vibration at the beginning of cutting. This result indicates that the normal stress near the line of uncut chip thickness, at which the sensor came in contact with the work material from the beginning of cutting because of a negative rake angle of $-5^{\circ}$, kept an almost constant value during cutting, while the cutting forces increased gradually until the tool-chip contact length reached to a value in steady state cutting. The saturated stress was approximately $200 \mathrm{MPa}$.

Except for an uncut chip thickness of $0.20 \mathrm{~mm}$, the normal stress showed quite different changes with cutting time for three uncut chip thicknesses of $0.05,0.10$, and $0.15 \mathrm{~mm}$. In case of an uncut chip thickness of $0.15 \mathrm{~mm}$ there was a short time lag between the start of cutting and a rapid increase in normal stress. The time lag was a time necessary for a produced chip to reach the position of the stress sensor by expanding the tool-chip contact area from the line of uncut chip thickness to the chip flow direction. After the normal stress increased rapidly, it continued to increase at reduced rate and finally became almost constant before the cutting came into a steady state. This suggests that the local stress there became steady state much faster than the cutting forces probably because the increase in tool-chip contact length had little influence on the local stress there. Note that the saturated normal stresses for uncut chip thicknesses of 0.15 and $0.20 \mathrm{~mm}$ were very close.

The time lag further increased at an uncut chip thickness of $0.10 \mathrm{~mm}$ because the distance from the line of uncut chip thickness to the sensor position increased with decreasing uncut chip thickness. It also took longer for the normal stress to reach a saturated value for the same reason. The saturated value of normal stress decreased largely when the uncut chip thickness was reduced from $0.15 \mathrm{~mm}$ to $0.10 \mathrm{~mm}$. In contrast, no obvious change in normal stress was found at an uncut chip thickness of $0.05 \mathrm{~mm}$. It seemed that the produced chip scarcely reached the stress sensor, which was 0.20 $\mathrm{mm}$ away from the cutting edge. That is, the produced chip left the tool rake face before arriving to the position of the sensor. This will be discussed next based on the data of Fig. 11.

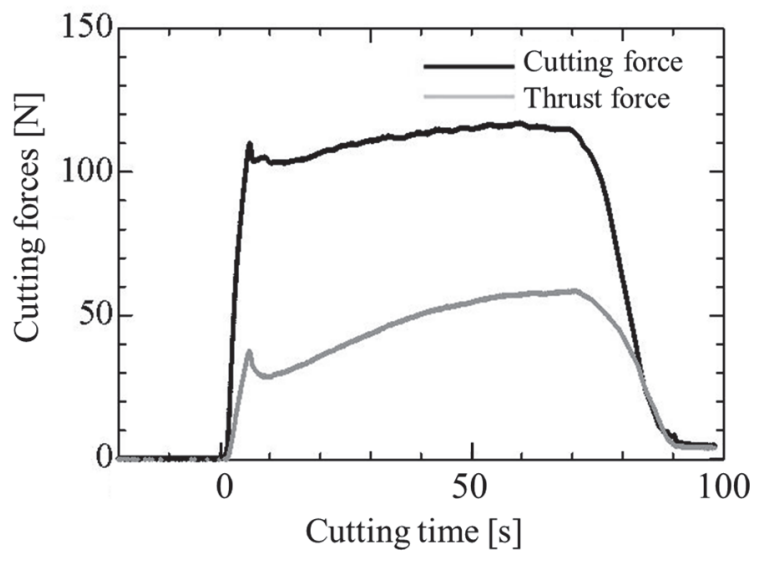

Fig. 9 Cutting and thrust forces obtained for the cutting of MC Nylon at uncut chip thickness $0.20 \mathrm{~mm}$.

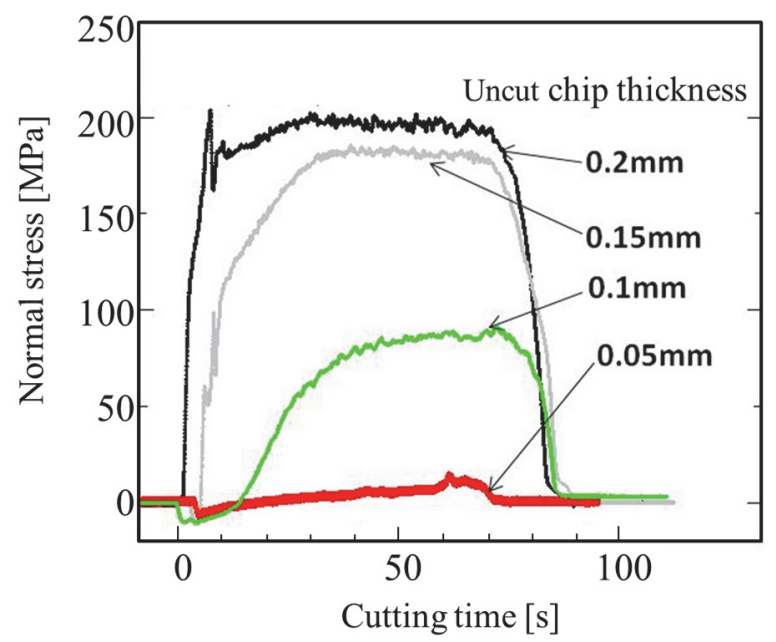

Fig. 10 Normal stresses obtained for the cutting of MC Nylon at four different uncut chip thicknesses. 
Figure 11 shows the normal stresses for three different uncut chip thicknesses at a cutting time of $60 \mathrm{~s}$ or a cutting distance of $6.0 \mathrm{~mm}$. They are plotted at different normalized positions of 1.0, 1.33, and 2.0, which are calculated by dividing the position of sensor from the cutting edge $0.2 \mathrm{~mm}$ by uncut chip thickness $0.20,0.15$, and $0.10 \mathrm{~mm}$, respectively. The width of each bar indicates the relative width of the stress sensor, which is also normalized by the corresponding uncut chip thickness. The mean tool-chip contact length was measured to be $0.48 \mathrm{~mm}$ for an uncut chip thickness of $0.20 \mathrm{~mm}$. Thus the normal stress at a normalized distance of 2.40 was assumed to be $0 \mathrm{MPa}$.

The cutting and thrust forces measured at cutting time $60 \mathrm{~s}$ were $118.3 \mathrm{~N}$ and $58.3 \mathrm{~N}$, respectively. From these data the normal force on the rake face with a rake angle of $-5^{\circ}$ was calculated to be $122.9 \mathrm{~N}$, and then, the mean normal stress $\sigma_{\mathrm{m}}$ was calculated to be $128.1 \mathrm{MPa}$ by taking into account that the tool-chip contact area was $0.96 \mathrm{~mm}^{2}$. Now, let us assume that a trapezoidal distribution can be applied to the normal stress for the orthogonal cutting of MC Nylon because this type of stress distribution was reported for the tool-chip interfaces in the machining of soft metals such as aluminum (Kato et al., 1972) and lead (Usui and Takeyama, 1960; Chandrasekaran and Kapoor, 1965). It is also because neither a constant normal stress distribution $\sigma_{\mathrm{m}}=128.1 \mathrm{MPa}$ nor a triangular normal stress distribution with a stress of $2 \sigma_{\mathrm{m}}=$ 256.2 $\mathrm{MPa}$ at the cutting edge can be apparently applied.

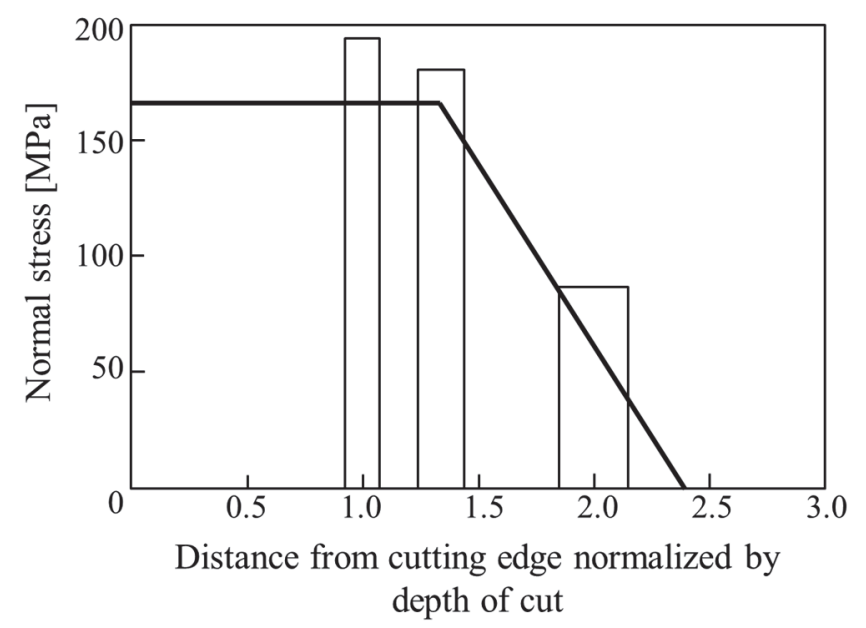

Fig. 11 Normal stresses measured for three different normalized distances from the cutting edge. Normalized distance is given by dividing the distance from the cutting edge to the sensor by uncut chip thickness. A trapezoidal stress distribution assumed for the orthogonal cutting of MC Nylon is also shown.

The trapezoidal distribution of normal stress $\sigma_{\mathrm{t}}$ is given by

$$
\sigma_{\mathrm{t}}= \begin{cases}\sigma_{\mathrm{E}} & \left(0 \leq l \leq l_{\mathrm{E}}\right) \\ \sigma_{\mathrm{E}}\left(\frac{l_{\mathrm{c}}-l}{l_{\mathrm{c}}-l_{\mathrm{E}}}\right) & \left(l_{\mathrm{E}}<l \leq l_{\mathrm{c}}\right)\end{cases}
$$

where $\sigma_{\mathrm{E}}$ is the normal stress at the cutting edge, $l$ is the normalized distance from the cutting edge, $l_{\mathrm{E}}$ is the normalized length of constant normal stress zone, and $l_{\mathrm{c}}$ is the normalized tool-chip contact length. From the force balance,

$$
\sigma_{\mathrm{m}} l_{\mathrm{c}}=\frac{1}{2} \sigma_{\mathrm{E}}\left(l_{\mathrm{c}}+l_{\mathrm{E}}\right)
$$

Elimination of $l_{\mathrm{E}}$ from Eq. (1) using Eq. (2) leads to

$$
\sigma_{\mathrm{t}}= \begin{cases}\sigma_{\mathrm{E}} & \left(0 \leq l \leq l_{\mathrm{E}}\right) \\ \frac{\sigma_{\mathrm{E}}^{2}}{\left(\sigma_{\mathrm{m}}-\sigma_{\mathrm{E}}\right)} \frac{\left(l_{\mathrm{c}}-l\right)}{2 l_{\mathrm{c}}} & \left(l_{\mathrm{E}}<l \leq l_{\mathrm{c}}\right)\end{cases}
$$


Finally, the value of $\sigma_{\mathrm{E}}$ was obtained to be $164.7 \mathrm{MPa}$ by the least square method. A thick line in Fig. 11 indicates the trapezoidal distribution most consistent with the experimentally obtained values of normal stress at three different normalized positions on the rake face. Although a small number of experimental data are used for the least square method and three measured stresses are 23.9 MPa larger than the assumed distribution on an average, this stress distribution would give an approximation for the cutting of MC Nylon.

Figure 12 shows the changes in the normal stress and cutting force obtained for the cutting of polyvinyl chloride at an uncut chip thickness of $0.2 \mathrm{~mm}$. Their wavy changes with cutting time seemed to synchronize with each other. The shape of a chip produced at an uncut chip thickness of $0.2 \mathrm{~mm}$ and for cutting length much longer than $8.0 \mathrm{~mm}$ is shown in Fig. 13. Obviously, a serrated chip accompanying periodically localized shears was formed in the cutting of polyvinyl chloride under the cutting conditions used. Generally, one of waves both in normal stress and cutting force corresponds to the formation of one segment of a serrated chip. It was clearly seen that the amplitude of waves was much larger for the normal stress than for the cutting force. This is because serrated chip formation caused localized shear periodically, resulting in the intensive change in chip deformation and stress on the rake face. Probably, once a localized shear occurs, the normal stress on the rake face would decrease abruptly as seen in Fig. 12.

The above results and discussion suggest that the thin film stress sensor fabricated on the tool face would capture the change in normal stress on the rake face during various chip formations such as serrated chip formation, discontinuous chip formation as well as the continuous chip formation. In addition to continuous cutting processes it may be applied to interrupted cutting processes which cause more dynamic changes in stresses on the tool faces if it is tough enough for mechanical and thermal impact during cutting. Such sensors could help us understand the mechanism of cutting from mechanical and dynamical viewpoints.

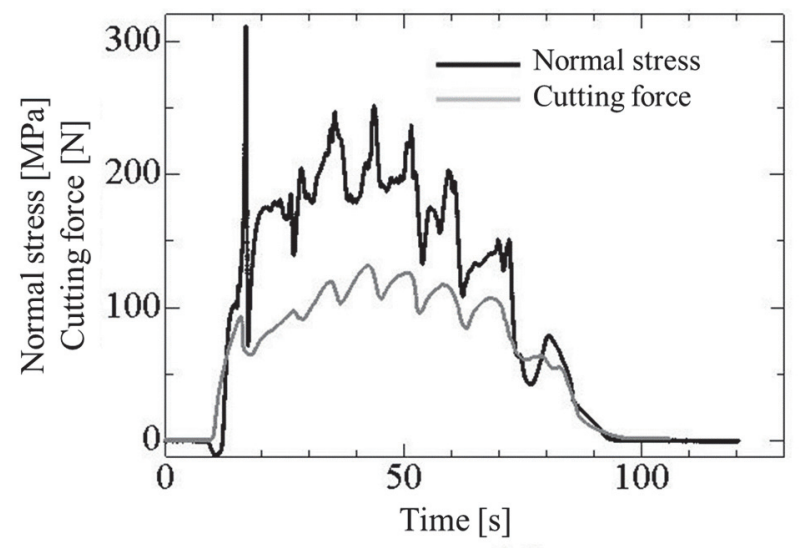

Fig. 12 Normal stress and cutting force obtained in cutting polyvinyl chloride at uncut chip thickness $0.2 \mathrm{~mm}$.

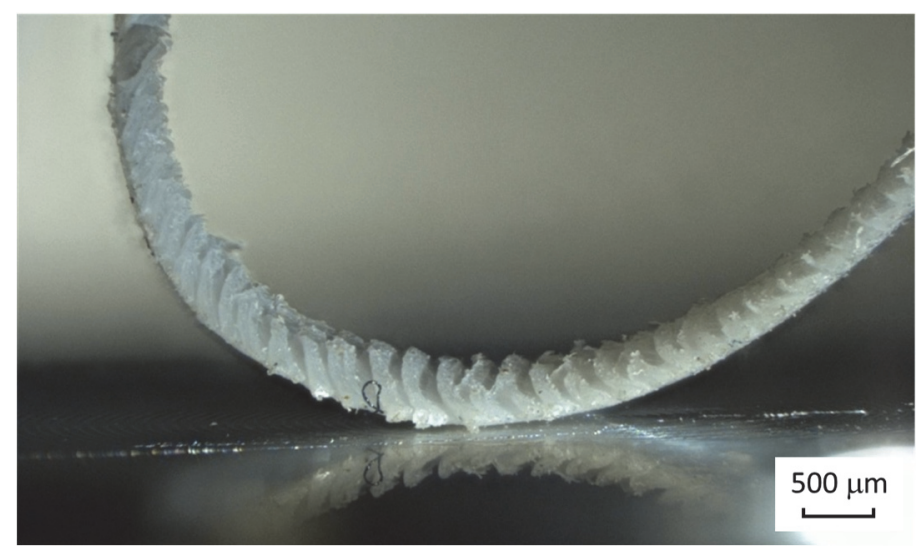

Fig. 13 Chip shape of polyvinyl chloride produced at uncut chip thickness $0.2 \mathrm{~mm}$. 


\section{Conclusions}

A tool with a thin film stress sensor of manganin in the coating layer structures was fabricated, and the normal stress acting on the rake face was measured with it in the orthogonal cutting of MC Nylon and polyvinyl chloride with the tool with a rake angle of $-5^{\circ}$. The following conclusions were obtained.

(1) The normal stresses obtained for the machining of MC Nylon at different uncut chip thicknesses showed specific changes according to the relative position between the sensor and uncut chip thickness. When the position of the sensor was very close to the uncut chip thickness, it was almost constant during cutting. In contrast, when the position of the sensor was farther away from the cutting edge than the uncut chip thickness, there was a time lag between the start of cutting and a rapid increase in normal stress, which was followed by a gradual increase to the steady value. These changes in the normal stress indicated that the thin film stress sensor could measure the stress acing on the tool rake face in flow type chip formation.

(2) The relationship between the measured normal stress and the normalized distance from the cutting edge was obtained. Then, a trapezoidal distribution was fitted to the relationship using cutting and thrust forces measured with a cutting dynamometer and the mean tool-chip contact length measured with a digital microscope as constraint conditions. This distribution gave a good approximation to the measured stresses of MC Nylon similarly to those of soft metals, which had been measured using photoelastic analysis or split tools.

(3) The normal stress obtained for the machining of polyvinyl chloride at an uncut chip thicknesses of $0.20 \mathrm{~mm}$ showed intense wavy change. This change with cutting time synchronized with measured cutting force and seemed correspond with the formation of segments of a serrated chip obtained. Abrupt decrease in normal stress repeatedly appeared should be attributed to localized shear observed in a serrated chip formation.

(4) From all the results, it was definitely shown that the thin film stress sensor could measure the stress on the rake face and would contribute to the understanding of the mechanics and dynamics of machining.

\section{Acknowledgements}

The author would like to acknowledge to Professor Masahiko Yoshino at Tokyo Institute of Technology for supporting the calibration of the thin film stress sensors.

\section{References}

Bagchi, A. and Wright, P. K., Stress analysis in machining with the use of sapphire tools, Proceedings of the Royal Society of London, Series A, Vol.409, No.1836 (1987), pp. 99-113. DOI:10.1098/rspa.1987.0008.

Basti, A., Obikawa, T. and Shinozuka, J., Tools with built-in thin film thermocouple sensors for monitoring cutting temperature, International Journal of Machine Tools and Manufacture, Vol.47, No.5 (2007), pp.793-798. DOI:10.1016/j.ijmachtools.2006.09.007.

Biehl, S., Lüthje, H., Bandorf, R. and Sick, J. H., Multifunctional thin film sensors based on amorphous diamond-like carbon for use in tribological applications, Thin Solid Films, Vol.515, (2006), pp.1171-1175. DOI:10.1016/j.tsf.2006.07.143.

Chandrasekaran, H. and Kapoor, D. V., Photoelastic analysis of tool-chip interface stresses, Journal of Engineering for Industry, Vol.87, No.4 (1965), pp.495-502.

Kato, S., Yamaguchi, K. and Yamada, M., Stress distribution at the interface between tool and chip in machining, Journal of Engineering for Industry, Vol.94, No.2 (1972), pp.683-689.

Mihara, Y., Motoki, H. and Someya, T., Measurement of contact pressure between two rollers using a thin-film sensors, Transactions of the Japan Society of Mechanical Engineers, Series C, Vol.76, No.761 (2010), pp.201-206 (in Japanese).

Obikawa, T. and Kani, B., Micro ball end milling of titanium alloy using a tool with a microstructured rake face, Journal of Advanced Mechanical Design, Systems and Manufacturing, Vol.6, No.7 (2012), pp.1121-1131. DOI:10.1299/jamdsm.6.1121.

Obikawa, T., Matsumura, T., Shirakashi, T. and Usui, E., Wear characteristic of alumina coated and alumina ceramic tools, Journal of Materials Processing Technology, Vol.63, (1997), pp.211-216. DOI:10.1016/S0924- 
0136(96)02626-X.

Obikawa, T. and Shinozuka, J., Monitoring of flank wear of coated tool in high speed machining with a neural network ART2, International Journal of Machine Tools and Manufacture, Vol.44, No.12 (2004), pp.1311-1318. DOI:10.1016/j.jimachtools.2004.04.021

Obikawa, T. and Usui, E., Computational machining of titanium alloy - finite element modeling and a few results, Journal of Manufacturing Science and Engineering, Vol.118, No.2 (1996), pp.208-215. DOI:10.1115/1.2831013

Ohbuchi, Y. and Obikawa, T., Finite element modeling of chip formation in the domain of negative rake angle cutting, Journal of Engineering Materials and Technology, Vol.125, No.3 (2003), pp.324-332. DOI:10.1115/1.1590999

Shinozuka, J., Basti, A. and Obikawa, T., Development of cutting tool with built-in thin film thermocouples for measuring high temperature fields in metal cutting processes, Journal of Manufacturing Science and Engineering, Vol.130, No.3 (2008), 034501. DOI:10.1115/1.2823066.

Usui, E., Shirakashi, T. and Kitagawa, T., Analytical prediction of three dimensional cutting process (part 3), Journal of Engineering for Industry, Vol.100, No.2 (1978), pp. 236-243. DOI:10.1115/1.3439415.

Usui, E. and Takeyama, H., A photoelastic analysis of machining stresses, Journal of Engineering for Industry, Vol.82, No.4 (1960), pp.303-307. DOI:10.1115/1.3664233. 